\title{
Scottish Paediatric Society
}

At the Annual General Meeting held in the Western General Hospital, Edinburgh on 23 November 1973, the President, Professor J. O. Forfar, was in the Chair. Dr. E. N. Coleman was re-elected Secretary and Treasurer.

The following clinical presentations were made:

Maple syrup urine disease and antenatal diagnosis. T. L. Turner (introduced). Royal Hospital for Sick Children, Edinburgh.

Paraquat poisoning with recovery. H. Simpson. Royal Hospital for Sick Children, Edinburgh.

Renal acidosis. I. Mitchell (introduced). Western General Hospital, Edinburgh.

Recurring pancreatitis in a diabetic child. Mhairi Macdonald (introduced). Royal Hospital for Sick Children, Edinburgh.

Management of the Sturge-Weber syndrome. G. Sandor (introduced). Royal Hospital for Sick Children, Edinburgh.

\section{Scientific communications}

Long-term radiological assessment of juvenile rheumatoid arthritis. K. M. Goel (introduced) and S. P. Rawson. Royal Hospital for Sick Children, Glasgow.

The radiological status of 50 patients with rheumatoid arthritis had been re-evaluated in a follow-up study ranging from 1 to 30 years. A skeletal survey had been compared with the radiographs taken at the onset of the disease and changes were graded according to severity (0-IV). A significant statistical association was found between the presence of moderate to severe radiographical changes and an age of onset of less than 6 years. A similar association was seen between severity of radiological changes and increasing duration of disease activity, an intermittent or continuous course (as opposed to monocyclic) (Goel and Shanks, 1974), poor functional status, physical deformity, splenomegaly, lymphadenopathy, and serological abnormalities (positive RoseWaaler test). Patients in a group treated with steroids showed a higher incidence of moderate or severe radiological changes. No association was observed between the radiological grade and rheumatoid rash, increased $\beta_{1} c / \beta_{1} \mathrm{~A}$ globulins, or the sex of the patient.

\section{REFERENCE}

Goel, K. M., and Shanks, R. A. (1974). Follow-up study of 100 cases of juvenile rheumatoid arthritis. Annals of the Rheumatic Diseases, 33, 25.

Plasma ethosuximide in epilepsy: clinical aid and illustration of principles. J. B. P. Stephenson, D. J. Clow (introduced), E. C. Jamieson (introduced), and R. W. Logan (introduced). Royal Hospital for Sick Children, Glasgow.
The authors had studied plasma ethosuximide concentrations in children with potentially ethosuximidesensitive epilepsies because the high seizure frequency, good EEG-seizure correlation, and relative safety of drug withdrawal promised more exact evaluation of the drug-epilepsy relation than was possible in convulsive seizures. The statistical data presented derived from 81 plasma ethosuximide measurements in 21 children over an 18-month period from November 1971, with further evidence on clinical effect and toxicity obtained at follow-up. There was an overall relation between dose and plasma level, but the latter could not be predicted in individual patients. Delayed drug accumulation was observed, in 1 case with the demonstration of a prolonged half life. Toxicity requiring dose reduction appeared only with plasma ethosuximide levels over $160 \mu \mathrm{g} / \mathrm{ml}$. The therapeutic range for simple and complicated absences and myoclonic epilepsies was 68 to $220 \mu \mathrm{g} / \mathrm{ml}$ and normal EEG indicated cure. As a result of the study, fewer children had seizures and fewer needed drugs. The study illustrated considerable variations between patients, and over a period of time in the same patient, in (1) the severity of the epilepsy, (2) drug resistance of the epilepsy, (3) ratio of plasma level to dose, and (4) toxic plasma concentration.

One year's experience in a paediatric nephrology unit. Anna V. Murphy. Royal Hospital for Sick Children, Glasgow.

In September 1972 an 8-bed paediatric nephrology unit opened in the Royal Hospital for Sick Children. Initially in use 5 days per week, this was increased to 7 days, with haemodialysis 6 days each week. Radiological and ultrasonic facilities were available with the Diasonograph NE 4101 being employed for pulsed nephrosonography (Lyons, Murphy, and Arneil, 1972). Isotope renography was available using an MS 510 Renography System modified for use in young infants. During the first year 260 children had been admitted on 350 occasions from a wide geographical area. The work had included isotope renography on 279 children, percutaneous renal biopsy on 49 children, nephrosonography on 65, and investigation of a urineless method of inulin clearance on 64. Peritoneal dialysis had been required for 6 patients in acute renal failure. 3 patients were currently on maintenance haemodialysis awaiting a suitable renal transplant. Close liaison with social workers and child psychiatrists had been maintained. Obstructive uropathies had been investigated in cooperation with paediatric urologists in the hospital. The unit had a dual role in the assessment and treatment of renal disease in children and as the paediatric component of an integrated assessment, dialysis, and transplant programme in the West of Scotland. 